\title{
Microstructure and Mechanical Properties in the Friction Stir Welded C70600 Alloy
}

\author{
Sung-Wook Chung*, ${ }^{*}$, Tai-Jin Yoon**, Joong-Suk Noh***, and Chung-Yun Kang** \\ *Welding Engineering R\&D group, Daewoo shipbuilding \& marine engineering Co., Ltd., 3370, \\ Geoje, 53302, Korea \\ **Division of Materials Science and Engineering, Pusan National University, Busan, 46241, Korea \\ ***Division of Engineering R\&D, Hanjoo Metal Co., Ltd., Ulsan, 45010, Korea
}

†Corresponding author : chungsw@dsme.co.kr

(Received August 21, 2017 ; Revised January 10, 2018 ; Accepted March 5, 2018)

\begin{abstract}
A friction stir welded (FSW-ed) C70600 alloy plate was partially welded to other C70600 alloy plate by the gas tungsten arc welding (GTAW). First, FSW was performed on the C70600 alloy by 2-steps (on the top and the bottom). The ultimate tensile strength after FSW was average 317MPa very close to that (average 324MPa) of GTAW-ed C70600 joint. The bending test results after FSW varied by the welding condition. Case A failed the bending test according to the ASME code (ASME Sec. IX) at the face bending because of relatively lower heat input (rotation speed/traveling speed was $600 \mathrm{rpm} / 200 \mathrm{~mm} / \mathrm{min}$ ) while Case B (higher heat input; rotation speed/ traveling speed was $1200 \mathrm{rpm} / 200 \mathrm{~mm} / \mathrm{min}$ ) met the requirements. There were characteristic microstructures such as black-arc-arrays of the oxides in the FSW stir zone (SZ) and the micro-pores in the boundary between FSW-SZ and GTAW weld metal (WM). The former was originated from the crushed and stirred oxides which pre-existed on the base metal surface. The latter could result from re-gasified $\mathrm{O}_{2}$ gas formed by $\mathrm{Cu}$ oxides melted at the boundary between FSW-SZ and GTAW-WM.
\end{abstract}

Key Words : Copper alloy, Mechanical properties, Microstructure, SEM, Friction stir welding

\section{Introduction}

Friction stir welding (Hereafter, FSW) which was invented by TWI ${ }^{1)}$ has been developed rapidly by its mechanical, environmental and economic advantages in various applications ${ }^{2)}$.

FSW on the copper or copper alloy has been researched by the industrial needs. Basic mechanical properties on oxygen-free coper (UNS C10200) after FSW were investigated $^{3)}$. Cu canister can be sealed effectively by FSW; 50mm thick copper part could be joined in 1 pass $^{4}$. The dissimilar joints such as $\mathrm{Cu}$ to $\mathrm{Al}$ or $\mathrm{Cu}$ to mild steel were reported ${ }^{5-6)}$. Ni-Al-Bronze (UNS CD95800) for the marine part increased its physical and mechanical properties by friction stir processing ${ }^{7-9)}$. There was a trial which was carried out FSW on the partially fusion-welded joint in pipeline steel application ${ }^{10)}$. Song et al. carried out a laser-assisted hybrid FSW on Inconel
600 alloy and reported that the microstrucrural evolution of dynamic recrystallization by increasing welding speed and subsequent enhanced mechanical properties $^{11)}$. In shipbuilding or marine engineering, FSW has been applied to make deck panels, helideck structure and some low-weight structures ${ }^{2}$. However, a trial to join a FSW- ed part to another part by conventional arc welding has not been reported yet while industrial demands increase.

In the piping system, $\mathrm{Cu}-\mathrm{Ni}$ alloys are known as the excellent materials for seawater process piping lines. Seawater is one of the main corrosive fluids and its pipeline requires high corrosion-resistance. $\mathrm{Cu}-\mathrm{Ni}$ is covered by condense oxide films which causes sufficient passivation for the marine salt water environment. Therefore, $\mathrm{Cu}-\mathrm{Ni}$ alloys are widely used in shipbuilding and marine applications such as pipes, fittings, valves, pump components and other marine hardware parts. Yoon et al. reported comprehensive study on FSW to

Journal of Welding and Joining, Vol.36 No.2(2018) pp60-66

https://doi.org/10.5781/JWJ.2018.36.2.9 
$\mathrm{Cu}-\mathrm{Ni}$ alloy ${ }^{12)}$. They revealed that the oxide layer $(\mathrm{NiO})$ on the base metal's surface was re-distributed in the stir zone (Hereafter, SZ) as agglomerate flakes with a diagonal arc shape after FSW. The joint efficiency was about $90 \%$ after FSW. They explained that the primary factor on the tensile fracture position was the brittle $\mathrm{NiO}$ in the $\mathrm{SZ}$.

In this work, $\mathrm{Cu}-\mathrm{Ni}$ alloy plates were friction-stirwelded at first and the mechanical properties were qualified as a seam-welded $\mathrm{Cu}-\mathrm{Ni}$ pipe according to the standards ${ }^{13,14)}$ for the seawater process piping system. Then, the gas tungsten arc welding (Hereafter, GTAW) followed on the FSW-ed weldment to investigate the effect of the conventional fusion welding on the FSW-ed joint. This research can be a reference to anyone who may want to join FSW-ed $\mathrm{Cu}-\mathrm{Ni}$ component to another part by conventional fusion welding.

\section{Experimental Procedure}

In this work, the base metal was ASTM B171 UNS No. C70600 alloy plate of $10 \mathrm{~mm}$ thickness (Hereafter, $\mathrm{C} 70600$ alloy $^{15)}$ ) and the chemical composition was listed in Table 1.

Firstly, FSW was carried out on the butt joint of two base metal plates. Secondly, FSW-ed plate was cut for each purposes (i.e., for the mechanical tests and for the GTAW). Thirdly, GTAW was performed on the leftover FSW-ed weldment by locating the weld center line perpendicular to the FSW center line. Fig. 1 shows the schematics of the process.

FSW was carried out in 2 combinations of the rotation speed $(\mathrm{R}, \mathrm{rpm}) /$ the travel speed $(\mathrm{V}, \mathrm{mm} / \mathrm{min})$ : Case A was $600 / 200$ and Case B was 1200/200. During the
FSW, the rotating tool's position was controlled equally and the atmosphere was $99.9 \%$ argon gas. Tool was made of W92-Ni-Fe alloy and probe length was $5.5 \mathrm{~mm}$. The first bead passed on the top side (i.e., face side) of butt-jointed two plates, then the second pass did on the backward side (i.e., root side). The FSW-ed plate was cut into two blocks; one was consumed for the mechanical tests such as tensile elongation test and bending test, and the other was prepared for the next GTAW welding with new base metal.

Fig. 2 shows the dimensions of the mechanical test specimens. One of this work's objectives is to investigate the soundness of the FSW-ed seam weld of the C70600 alloy pipe, therefore quality of the weld should meet the requirements of the international code of

Tensile specimen

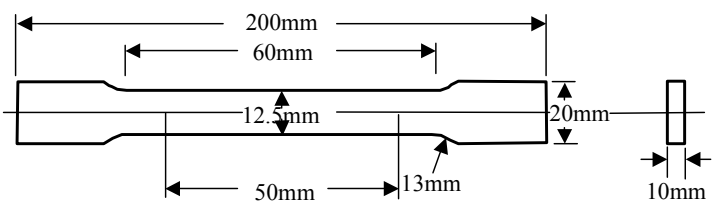

Guided bending specimen

Transverse face bend

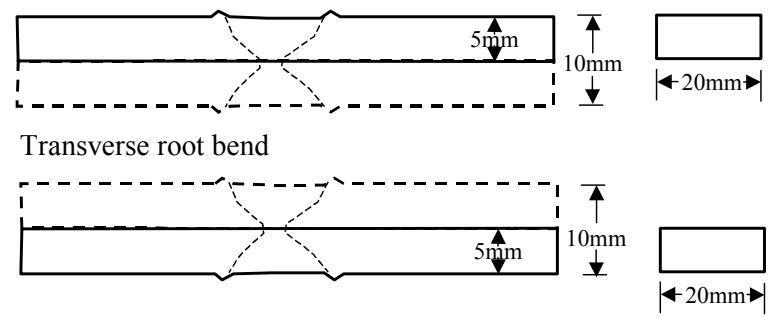

Fig. 2 Drawing of the tensile specimen (ASTM A370) and the bending specimen (ASME Section IX QW-462.3(a))

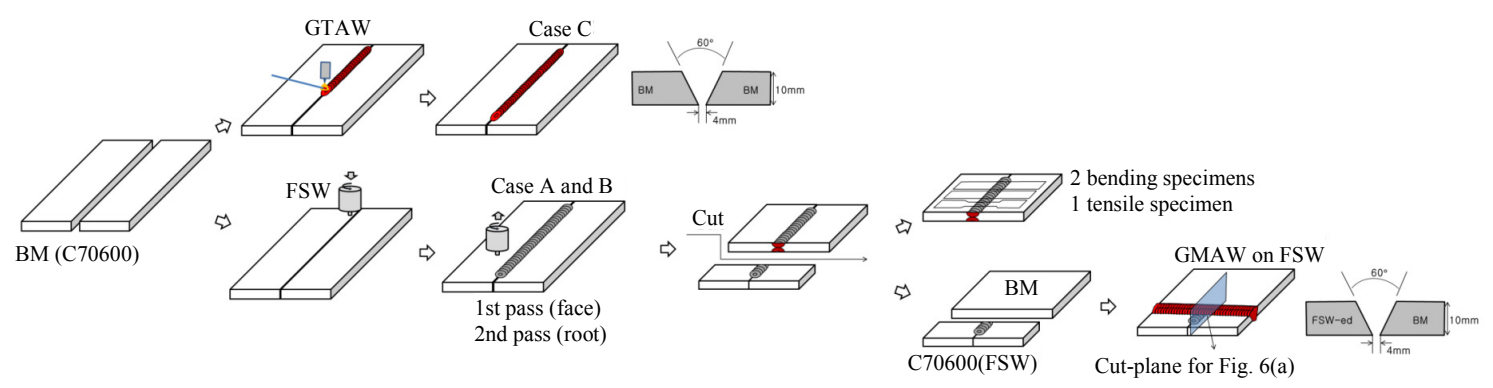

Fig. 1 Schematic process of this work

Table 1 Chemical compositions of the base metal and GTAW filler material (wt.\%)

\begin{tabular}{|c|c|c|c|c|c|c|c|c|}
\hline & $\mathrm{Cu}$ & $\mathrm{Ni}$ & $\mathrm{Mn}$ & $\mathrm{Fe}$ & $\mathrm{Zn}$ & $\mathrm{Pb}$ & $\mathrm{Ti}$ & Others \\
\hline Base Metal & $\mathrm{Bal}$. & 10.01 & 0.57 & 1.56 & 0.02 & 0.004 & & \\
\hline Filler & 67.5 & 30.5 & 0.75 & 0.52 & & 0.002 & 0.38 & $<0.5$ \\
\hline
\end{tabular}


Table 2 Welding conditions (FSW and GTAW)

\begin{tabular}{|l|l|l|l|}
\hline \multicolumn{2}{|l|}{ FSW } & \multicolumn{2}{l|}{ GTAW } \\
\hline Base metal & $90-10 \mathrm{CuNi}$ alloy (UNS C70600) & Base metal & $90-10$ CuNi alloy (UNS C70600) \\
\hline Tool Material & W92-Ni-Fe alloy & Welding Filler & ASME SFA 5.7 ERCuNi \\
\hline Shielding Gas & $99.9 \% \mathrm{Ar}$ & Shielding Gas & $99.9 \% \mathrm{Ar}$ \\
\hline Probe length, $\mathrm{mm}$ & 5.5 & Gas flow rate, liter/min & $10 \sim 15$ \\
\hline Rotation speed, rpm & $600($ Case A) and 1200 (Case B) & Current, A & $80 \sim 190$ \\
\hline Traveling speed, $\mathrm{mm} / \mathrm{min}$ & $200($ Cases A and B) & Voltage, V & $7 \sim 18$ \\
\hline & & Speed, $\mathrm{mm} / \mathrm{min}$ & $40 \sim 180$ \\
\hline
\end{tabular}

ASME Sec. IX ${ }^{14)}$. Tensile specimen's dimension was machined according to ASTM A370 ${ }^{13)}$ to compare the mechanical properties with that of the base metal. The gauge length was $50 \mathrm{~mm}$ and the gauge width was $12.5 \mathrm{~mm}$ for the FSW-ed samples. Guided bend test specimens were prepared by FSW-ed C70600 alloy plate in order to qualify the soundness of FSW weldment according to ASME Sec. IX. According to ASME Sec. IX QW. 462.3(a), a bending test specimen should be machined according to its thickness; one above $10 \mathrm{~mm}$ thickness requires the side bending specimens, but the other below $10 \mathrm{~mm}$ thickness requires a set of face and root bending specimens. The guided bend specimens were machined on both sides of the transverse face and the transverse root in this work. The thickness of the bend specimens was $5 \mathrm{~mm}$ and guide roller's radius was $20 \mathrm{~mm}$.

The leftover FSW-ed plate was fitted-up with new base metal for the next welding step (GTAW on FSWed plate). The general welding condition was the welding current of $150 \mathrm{~A}$, the voltage of $15 \mathrm{~V}$ and the welding speed of $140 \mathrm{~mm} / \mathrm{min}$. It is noted that GTAW filler is different from the base metal $(\mathrm{Cu}: \mathrm{Ni}=67.5: 30.5 \mathrm{wt} \%$ in Table 1) as an conventional practice because this filler shows better performance of the weldment. The details of two welding processes (FSW and GTAW) were listed in Table 2. After GTAW, the transection including FSW and GTAW weldment was cut, polished and etched with etchant (Dist. water $80 \mathrm{ml}$, sulfuric acid $5 \mathrm{ml}$, potassium dichromate $10 \mathrm{~g}^{16)}$ ) for the optical microscopic analysis with Zeiss AXIOSKOP 2 MAT. Further comprehensive microstructural analyses were carried out by using the scanning electronic microscopy (SEM), X-ray diffraction (EDS) and the electron probe micro-analysis (EPMA) to investigate the inclusions in SZ and micro-pores existing in the boundary between GTAW-WM and FSW-SZ.

\section{Result and Discussion}

Table 3 and Fig. 3 show the tensile test results of FSW-ed (Cases A and B in Fig. 3 (a) and (b)) and GTAW-ed (Case $\mathrm{C} 1$ and $\mathrm{C} 2$ in Fig. 3 (c) and (d)) C70600 alloy plate. Base metal's tensile result was quoted from the manufacturer's material certificates. Yield stress (YS) results after welding (both FSW and GTAW) increased when compared to the base metal while the ultimate tensile strength (UTS) were all similar between $314.4 \sim 324.6 \mathrm{MPa}$. It is noted that tensile elongation (TE) decreased from 39\% (base metal) to $\sim 35 \%$ after GTAW and 21 26\% after FSW. Fracture positions of the tensile specimen were the base metal (BM) portion for GTAW-ed samples (Fig. 3 (c) and (d)) while those were at the SZ for FSW-ed samples (Fig. 3 (a) and (b)). Generally, transversal tensile test on a welded joint requires only UTS because the gauge portion is a mixture of the base metal and the weldment. All results of FSW-ed and GTAW-ed samples met the requirements (minimum UTS is $275 \mathrm{MPa}$ ) according to the base metal's standard ${ }^{16)}$.

Table 3 Mechanical properties: base metal, FSW-ed samples (Cases A and B) and GTAW-ed samples (Case C)

\begin{tabular}{|c|c|c|c|c|c|c|}
\hline \multicolumn{1}{|c|}{ Sample } & \multicolumn{3}{|c|}{ Tensile elongation test } & \multicolumn{2}{c|}{ Bending test } \\
\hline Yase metal (C70600) & 173 & $\begin{array}{c}\text { Ultimate tensile } \\
\text { strength, MPa }\end{array}$ & $\begin{array}{c}\text { Elongation, } \\
\%\end{array}$ & $\begin{array}{c}\text { Fracture } \\
\text { position }\end{array}$ & Face & Root \\
\hline Case A (FSW 600/200) & 199.6 & 321 & 39 & BM & N/A & N/A \\
\hline Case B (FSW 1200/200) & 203.2 & 314.4 & 26.2 & SZ & Fail & Accept \\
\hline Case C1 (GTAW only) & 194.5 & 320.2 & 21.8 & SZ & Accept & Accept \\
\hline Case C2 (GTAW only) & 183.9 & 324.6 & 35.4 & HAZ & Accept & Accept \\
\hline
\end{tabular}




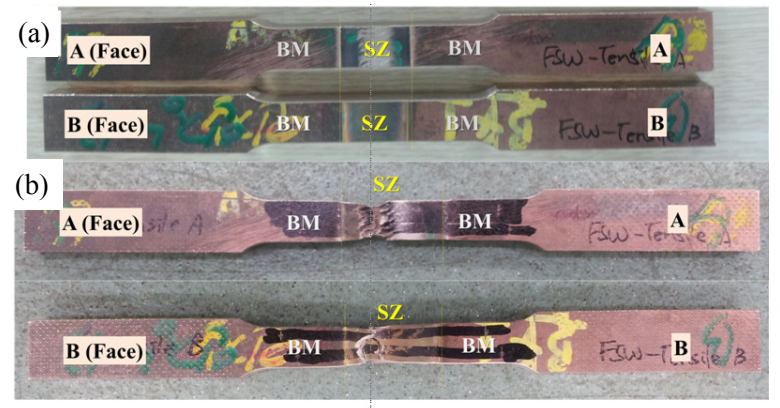

(c)

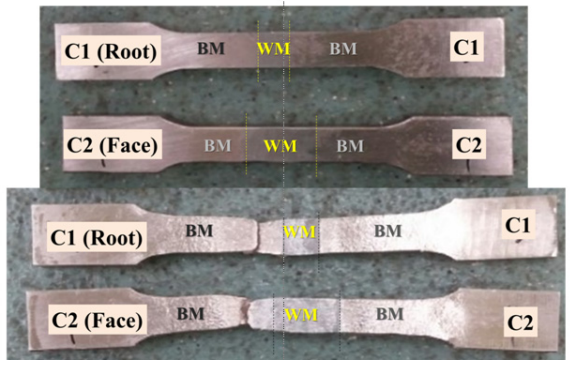

Fig. 3 Tensile test specimens; FSW-ed samples (a) before and (b) after the test, and GTAW-ed samples (c) before and (d) after the test

The change of TE can be explained by the characteristics of the welding joints. GTAW WM in practical use may have different chemical compositions to attribute better welding performance. The GTAW filler in this work belongs to UNS C71500 which has around 30\% higher tensile strength than C70600. As a result, BM portion should be elongated and fractured prior to WM. The tensile-fractured specimens for GTAW-ed samples (Fig. 3 (d)) showed that the deformation band covered BM's surfaces widely except the portion of WM. Similar UTS values of BM and GTAW-ed samples supports above explanation in Table 3. On the other hand, negligible deformation band existed in the surface of BM portion for FSW-ed samples while most deformation occurred at the surface of SZ portion (Fig. 3 (c)). Therefore, the actual tensile-elongated area was BM portions for GTAW-ed samples, on the other hand, it was SZ portions for FSW-ed samples. It's the reason why TE of FSW-ed samples showed much lower than BM and why GTAW-ed samples showed slightly lower than BM in Table 3.

Fig. 4 shows the pictures of tensile fracture behavior of cases A and B. Case A showed two distinct fracture faces; one is the dark-colored multi-layers near the face-side weld bead (upper area of the fracture faces in Fig. 4 (b)) and the other is bright-colored diagonal fracture (large portion of the fracture face). On the other hand, Case B showed diagonal fracture face normally (Fig. 4 (c) and (d)). The fracture positions of cases A and B were SZ and side profile was diagonal along the tensile direction. The dark-colored area covering 2$3 \mathrm{~mm}$ from the top surface of Case A existed on the frac-

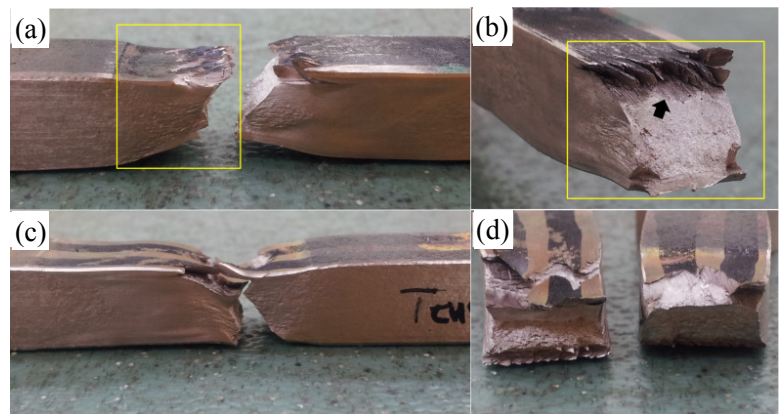

Fig. 4 Fractured tensile samples: (a) side profile and (b) fracture face of Case A, and (c) side profile and (d) fracture faces of Case B.

ture face (see the black arrow in the yellow box in Fig. 4 (b)). This dark-colored area showed a characteristic fracture profile which had multiple curvy layers diagonally. The similar pattern in SZ was observed as the oxide films distributed along the stirring metal flow by EPMA $^{12)}$.

Fig. 5 shows the results of bending test on FSW-ed specimens. Among 4 specimens, which were face- and
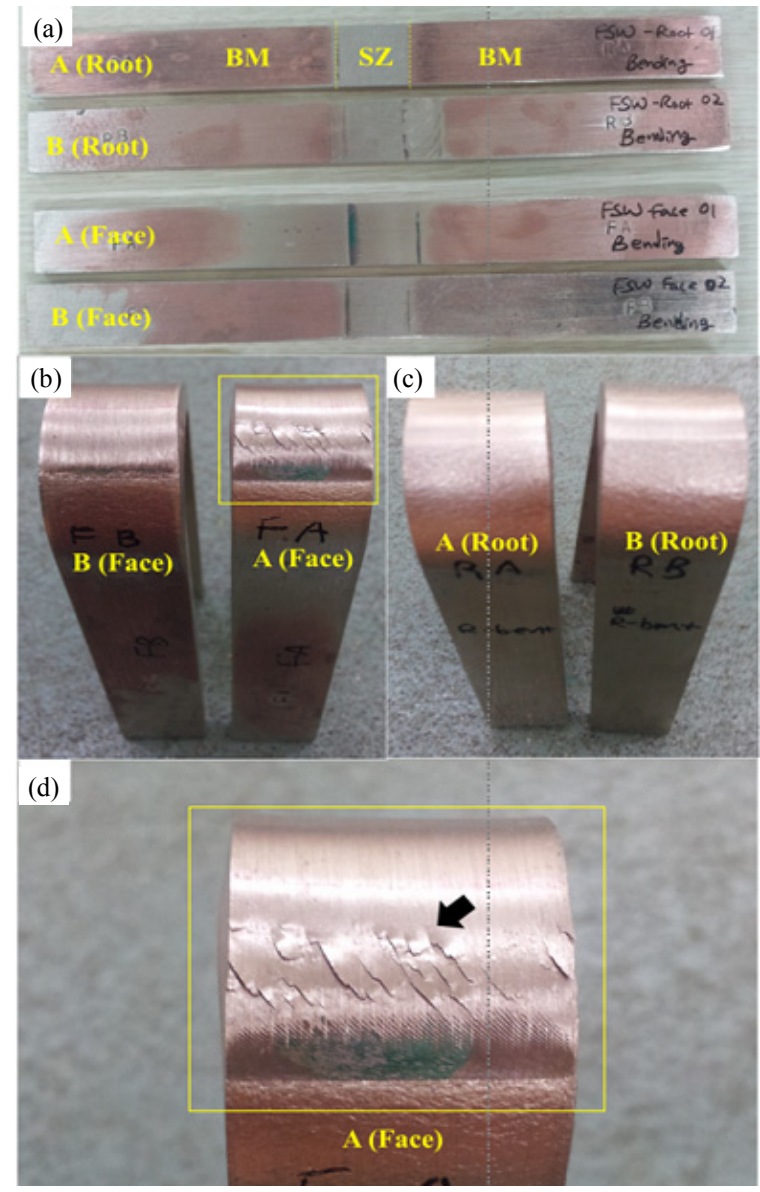

Fig. 5 Guided bending test; (a) specimens before the test, (b) face-side samples and (c) root-side samples after guided bending test, and (d) close-up picture of the face-side Case A sample 
root-bending on cases $\mathrm{A}$ and $\mathrm{B}$, the transverse face bend on case A (Fig. 5 (b)) failed the requirements because the surface cracks longer than $3 \mathrm{~mm}$ occurred diagonally while others were all satisfied. Generally, a crack during the bending test occurred with an improper fusion in welding. In this work, this characteristic feature of the array of the diagonal cracks could be explained by the lack of fusion in SZ. It is reasonable that these surface cracks in bending test resulted from the oxide film layers distributed in SZ during FSW. The oxide film layers in SZ also contributed the fracture position of tensile test. It is noted that UTS of FSW were as high as the base metal in spite of the oxide film layers covering $2 \sim 3 \mathrm{~mm}$ on the fracture face.

Fig. 6 (a) shows the macroscopic picture of GTAW on the FSW-ed CuNi plate. In the center of the Fig. 6 (a), a

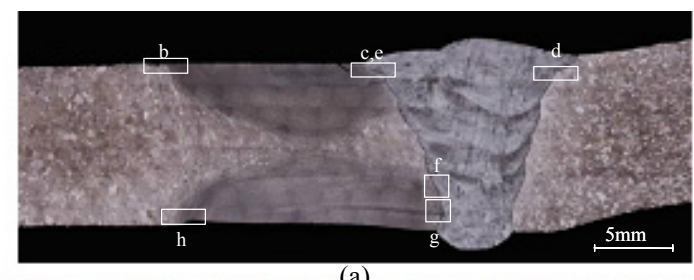

(a)

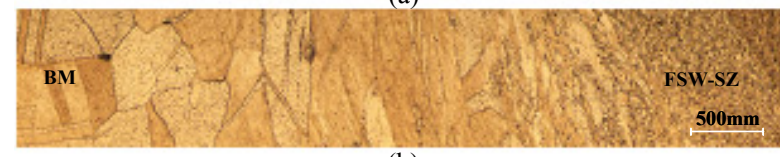

(b)

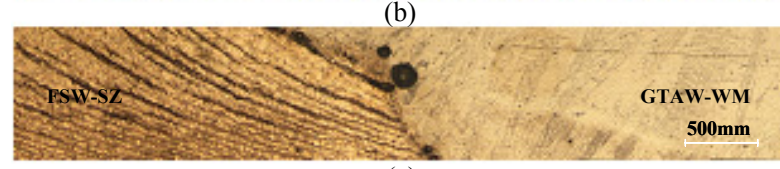

(c)

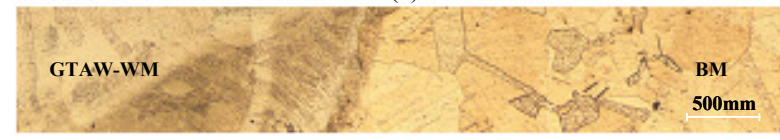

(d)

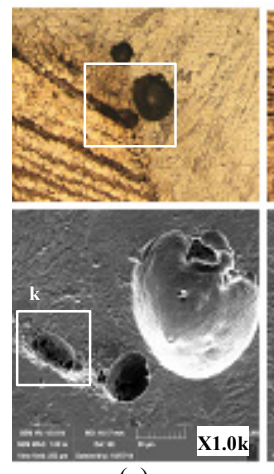

(e)

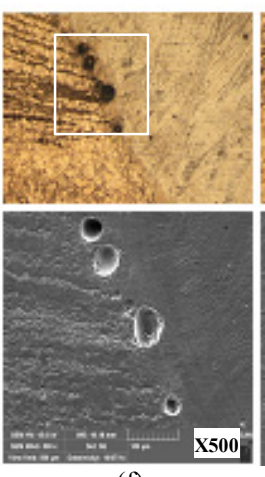

(f)

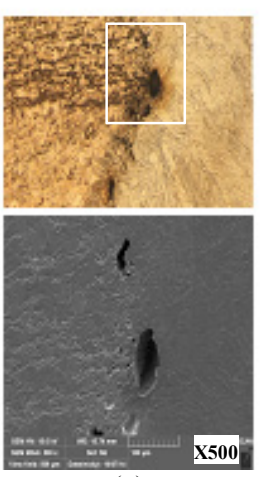

(g)
Fig. 6 Macro- and Micro- structures of FSW-ed and GTAW-ed C70600 butt joint; (a) full scale macro-image, (b), (c), (d) micro-images of the boundaries (BM//FSW-SZ, FSW-SZ//GTAW-WM and GTAW-WM//BM, respectively), (e), (f), (g) micro-pores along the boundaries between FSWSZ//GTAW-WM 'sandglass'-like SZ was made by double-side FSW. The left of the Fig. 6 (b) shows the microstructure of base metal (same as in the right of the Fig. 6 (d)). C70600 base metal has the grains ranging from 100 to $700 \mathrm{mi}-$ crons with some annealing twins. Typical GTAW-WM neighbored right side of FSW-SZ and formed partly-overlapped position (marked as "c, e, f and g" in Fig. 6 (a)). Either FSW or GTAW with the C70600 base metal showed sound weldment without any defect (Fig. 6 (b) and (d)).

Fig. 6 (c) shows characteristic microstructures. One is directionally ordered 'black-arc-arrays' on the left side. The others are micro-pores (also shown in Fig. 3 (e) (g)) along the FSW-SZ and GTAW-WM boundary. Those pores sized $10 \sim 100$ microns and most of them existed at the end of black-arc-arrays along the boundary of FSW-SZ and GTAW-WM. The black-arc-arrays formed during FSW since those arc arrays are in the same direction of stirring by the probe, and base metal had no precipitate to form those 'black-arc-arrays' also. It was hard to oxidize during FSW because FSW had been carried out in the $99.9 \%$ Ar atmosphere. In this work, the black-arc-arrays acted as a critical role of the tensile fracture and the cracking in bending test. The characteristic behaviors of the mechanical test (i.e., the dark-colored area in the tensile fracture surface and the diagonal array of cracks in the bending specimen in the face bend of sample A) resulted from this microstructure. It is widely known that the oxide film on the surface of the metal plate crushes and stirs during $\mathrm{FSW}^{17)}$ and Yoon et al. revealed that re-distributed agglomerates of $\mathrm{NiO}$ oxides in $\mathrm{SZ}$ could act as a role of tensile fracture ${ }^{12)}$. In this work, C70600 base metal plate also had oxide films on the surface in Fig. 7 (a) where indicates a cut-plane parallel to the FSW welding direction (see the mark ' $h$ ' in Fig. 6 (a)). In Fig. 7 (a), the oxide layer (a mixture of Ni- and $\mathrm{Cu}$-oxides) was detected by EPMA element mapping. The thickness of the oxide layer was $\sim 30$ microns on the base metal surface while it decreased to 3 5 microns on the surfaces of SZ, TMAZ and HAZ. In Fig. 7 (b), the major elements of the blackarc-arrays were revealed as $\mathrm{Ni}$ and $\mathrm{O}$. According to Yoon et al., it is expected that $\mathrm{NiO}$ was the most favored by its lowest free energy among the oxides of $\mathrm{CuO}, \mathrm{Cu}_{2} \mathrm{O}$ and $\mathrm{NiO}$. The next possible oxide was $\mathrm{Cu}_{2} \mathrm{O}$ than $\mathrm{CuO}$ having the highest free energy. Therefore, the black-arc-arrays in Fig. 6 (c) were stirred and re-distributed oxide flakes (mostly $\mathrm{NiO}$ and less $\mathrm{Cu}_{2} \mathrm{O}$ ) which had existed on the surface of $\mathrm{C} 70600$ plate.

Fig. 8 (a) and (b) show high magnitude SEM images of the micro-pore on the position ' $k$ ' in Fig. 6 (e). There were micro-scale flakes in the micro-pore. By EDS, the 

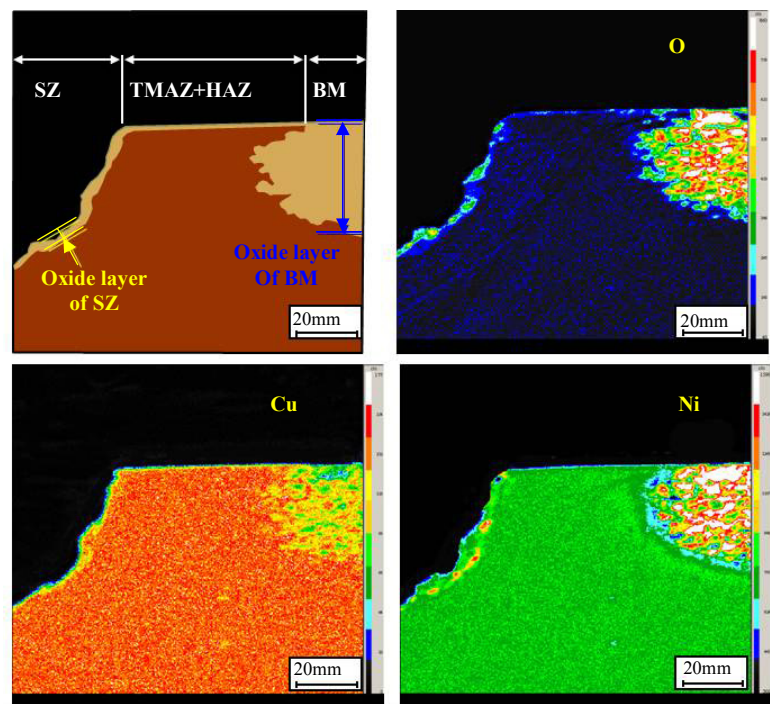

(a)
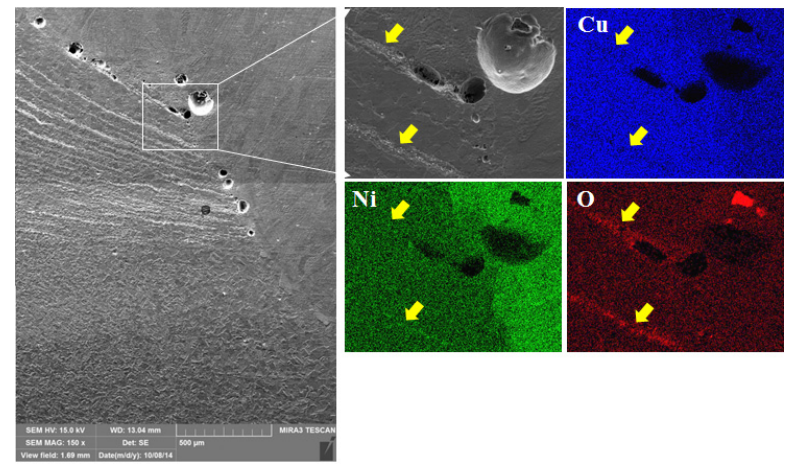

(b)

Fig. 7 EPMA element mapping on the edge of FSW (a) and on the area containing the black-arc-arrays neighbored to the FSW-GTAW boundary (b)

flakes were Ni-rich oxides and the inner surface of the micro-pore was similar to the base metal. The base metal $(\mathrm{Cu}: \mathrm{Ni}=90: 10$ wt.\%) and the filler metal $(\mathrm{Cu}: \mathrm{Ni}=$ 68:30 wt.\%) are fully soluble each other since C70600 alloy is a homogeneous solid solution as shown Fig. 6 (d). On the other hand, the boundary between FSW-SZ and GTAW-WM included a lot of micro-pores (Fig. 6 (c), (e) to (g)). The formation of the pores can be explained by the melting of $\mathrm{Cu}_{2} \mathrm{O}$ oxide which has contacted to GTAW molten pool. In GTAW, an arc generated from the tungsten electrode is a plasma state of very high temperature above $3000{ }^{\circ} \mathrm{C}^{18)}$. The temperature of GTAW weld pool should be sufficiently high enough to melt the filler and to flow the weld pool. The liquidus $\left(\mathrm{T}_{\mathrm{LF}}\right)$ of GTAW filler's equivalent material (UNS C71500, $\mathrm{Cu}: \mathrm{Ni}=70: 30$ wt.\%) is $1238{ }^{\circ} \mathrm{C}^{19}$ ), which is higher or close to that of $\mathrm{Cu}_{2} \mathrm{O}\left(\mathrm{T}_{\mathrm{L}, \mathrm{Cu} 2 \mathrm{O}}=1235{ }^{\circ} \mathrm{C}\right.$ 20). On the other hand, it becomes much more hard to melt $\mathrm{NiO}\left(\mathrm{T}_{\mathrm{L}, \mathrm{NiO}}=1955{ }^{\circ} \mathrm{C}^{20)}\right)$. According to the inves-

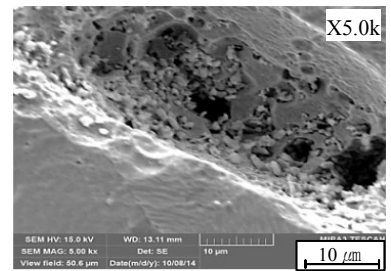

(a)

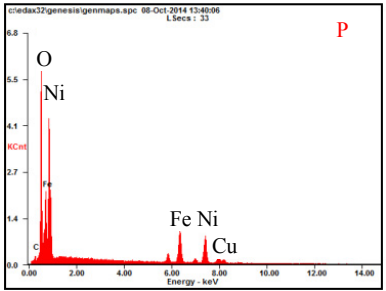

(c)

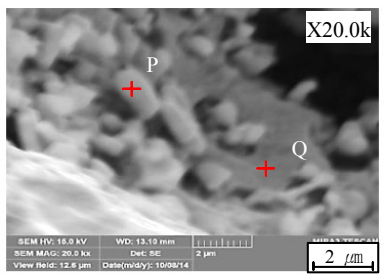

(b)

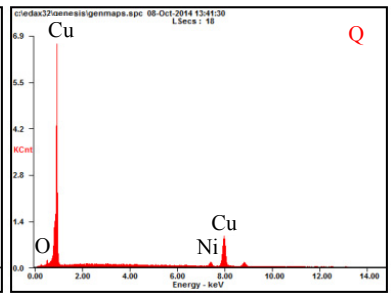

(d)
Fig. 8 SEM and EDS results: (a) SEM image focusing the micro-pore $(\mathrm{X} 5.0 \mathrm{k}),(\mathrm{b})$ oxide flakes (point $\mathrm{P}$ ) and inner surface (point Q) of the pore (X20.0k), (d) and (e) EDS peaks on the point P and Q

tigation on the macrosegregation by dissimilar filler metals, the thin boundary (called as 'the filler-rich zone, ${ }^{21)}$ ) between the bulk WM and BM (in this work, FSW-SZ) freezes quickly. Fast cooling of the filler-rich zone resulted in trapping effect subject to $\mathrm{O}_{2}$ gas formed from the end of the oxide flakes (i.e., the blackarc-arrays) neighbored to the molten pool. Therefore, most pores existed along the filler-rich zone between FSW-SZ and GTAW-WM (Fig. 6 (c), (e) to (g)). EDS peaks on the oxide flakes (point $\mathrm{P}$ ) and inner wall (point Q) support above explanation (Fig. 8 (c) and (d)). The EDS peak of oxide flakes showed mainly $\mathrm{Ni}$ oxide while copper oxides were very weak.

\section{Summary}

1) FSW and subsequent GTAW were tried to C70600 alloy plates. Each welding process was qualified by mechanical tests according to the international standards. Tensile properties after FSW were close to the base metal and GTAW-ed weldment. A sample of relatively low heat input (Case A; rotation speed 600rpm and traveling speed $200 \mathrm{~mm} / \mathrm{min}$ ) failed in transverse face bending test because of the existence of oxide films in the FSW SZ.

2) The overlapped weldment (FSW-ed then GTAW-ed) was investigated to clarify the effect of GTAW on FSW SZ. It was revealed that GTAW on the FSW SZ formed the micro-pores along the boundary between FSW SZ and GTAW WM. It is explained by that $\mathrm{O}_{2}$ gas formation by melting of low liquidus oxides $\left(\mathrm{Cu}_{2} \mathrm{O}\right)$ from the oxide flakes $\left(\mathrm{Cu}_{2} \mathrm{O}\right.$ and $\left.\mathrm{NiO}\right)$ which were contacted 
to the boundary between FSW SZ and GTAW WM.

\section{Acknowledgement}

This work has been supported in part by a grant from MOTIE Project No. 10046526.

ORCID: Sung Wook Chung: http://orcid.org/0000-0003-3367-8398 ORCID: Joong Suk, Noh: http://orcid.org/0000-0001-7599-2583 ORCID: Chung Yun Kang: http://orcid.org/0000-0003-1122-5320

\section{References}

1. T. M. Wayne, E. D. Nicholas, J. C. Needham, M. G. Murch, P. Temle-smith, C. J. Dawes, European Patent No. EP0615480 (1991)

2. B. R. Singh, A Handbook of FSW, LAP LAMBERT Academic Pub., Saarbruken (2012), 151-163

3. H. S. Park, B. W. Lee, Microstructures and Mechanical Properties of Friction Stir Welds of Oxygen Free Copper, Journal of KWJS , 23(1), (2005), 77-85

4. L. Cederqvist, O. Garpinger, T. Hagglund, A. Robertsson, Friction Stir Welding and Processing VI, (ed. R. Mishra, M. W. Mahorney, Y. Sato, Y. Hovanski, R. Verma), TMS, Hoboken (2011), 51-58

5. R. Sarrafi, A. H. Kokabi, M. A. Gharacheh, B. Shalchi, Friction Stir Welding and Processing VI, (ed. R. Mishra, M. W. Mahorney, Y. Sato, Y. Hovanski, R. Verma), TMS, Hoboken (2011), 253-264

6. M. Shamsujjoha, B. K. Jasthi, M. west, C. Widener, Friction Stir Welding and Processing VII, (ed. R. Mishra, M. W. Mahorney, Y. Sato, Y. Hovanski, R. Verma), TMS, Hoboken (2013), 151-160

7. S. K. Menon, C. J. England, T. R. McNelley, Friction Stir Welding and Processing VI, (ed. R. Mishra, M. W. Mahorney, Y. Sato, Y. Hovanski, R. Verma), TMS, Hoboken (2011), 89-95

8. L. Christodoulou, W. Palko, C. Fuller, Friction Stir Welding and Processing III, (ed. K. V. Jata, M. W. Mahorney, R. S. Mishra, T. J. Lienert), TMS, Hoboken (2005), 57-66

9. K. Oh-ishi, A. P. Zhilyaev, R. Williams, T. R. McNelley, Friction Stir Welding and Processing III, (ed. K. V. Jata, M. W. Mahorney, R. S. Mishra, T. J. Lienert), TMS, Hoboken (2005), 107-114
10. M. Mahoney, S. Sanderson, Z. Feng, R. Steel, S. Packer, F. Dale, Friction Stir Welding and Processing VII, (ed. R. Mishra, M. W. Mahorney, Y. Sato, Y. Hovanski, R. Verma), TMS, Hoboken (2013), 59-69

11. K. H. Song, T. Tsumura, K. Nakata, Development of Microstructure and Mechanical Properties in LaserFSW Hybrid Welded Inconel 600, Materials Trans. 50 (7) (2009), 1832-1837 https://doi.org/10.2320/matertrans.M2009058

12. T. J. Yoon, S. W. Park, S. W. Chung, J. S. Noh, K. H. Kim, C. Y. Kang, The effect of surface oxidation layer on tensile strength of $\mathrm{Cu}-\mathrm{Ni}$ alloy in friction stir welding, Met. Mater. Int. 22(3) (2016), 501-508 https://doi.org/10.1007/s12540-016-5620-x

13. ASTM A370-03, Standard Test Methods and Definitions for Mechanical Testing of Steel Products, ASTM International, West Conshohocken. PA 19428-2959. USA (2003), 5

14. ASME Sec. IX, Qualification Standard for Welding and Brazing Procedures, Welders, Brazers, and Welding and Brazing Operators, ASME Boiler and Pressure Vessel Code, QW-160, Three Park Avenue, New York, USA (2010), 5

15. ASTM B171-99, Standard Specification for CopperAlloy Plate and Sheet for Pressure Vessels, Condensers, and Heat Exchangers, ASTM International, West Conshohocken. PA 19428-2959. USA (1999), 3

16. G. Petzow, Metallographic Etching, 658, ASM, Metals Park (1978)

17. R. Zettler, T. Vugrin, M. Schmucker, Friction stir welding from basis to applications, (ed. D. Lohwasser, Z. Chen), Woodhead Pub., New Delhi, India (2010), 265272

18. D. Farson, R. Richardson, X. Li, Infrared Measurement of Base Metal Temperature in Gas Tungsten Arc Welding, Welding J. 77 (1998), 396-401

19. K. Ferjutz, J. R. Davis, Metals Handbook Vol.6 Welding brazing and soldering $10^{\text {th }}$ Ed., ASM International (1993). 1875

20. D. R. Lide, CRC Handbook of Chemistry and Physics, CRC Press, Boca Raton, FL, USA (2005), 757-774

21. Y. K. Yang and S. Kou, Weld-Bottom Macrosegregation Caused by Dissimilar Filler Metals, Welding J. 86 (2007), 379-387 